\title{
ABSORPTION OF GASES BY THE ANODE IN A GLOW CURRENT.
}

By V. L. Chrisler.

TH

HE first quantitative measurements on the absorption of gases under a glow current appear to have been made by Mey ${ }^{1}$ who used a sodium-potassium alloy as cathode for purifying helium. Riecke $^{2}$ also passed a current for several hours through an atmosphere of nitrogen and measured the decrease in gas pressure. Neither of these observers found any electrolytic relation between the rate of absorption and the electric current. Skinner, ${ }^{3}$ however, found later that most fresh metals when used as cathode with a glow current in helium or argon gave off hydrogen for a few minutes at the rate required by Faraday's law for electrolytes, while in hydrogen the pressure remained practically constant. He explained the absence of an increase in pressure in hydrogen by assuming that the cathode gave off gas at the same rate in hydrogen as in helium but that the anode absorbed it for a time at an equal rate. From experiments performed in a nitrogen atmosphere ${ }^{4}$ he concluded that it also was absorbed by the anode for a time at the same rate as hydrogen.

The object of the present investigation was to obtain by a direct test the rate of absorption of these gases by the anode. The plan followed was to use a cathode which had previously been sufficiently freed of its content of gas so that it contributed nothing appreciable to the change in pressure. Then the effect of absorption at the anode could be directly obtained from the decrease in the pressure of the gas in the system. ${ }^{5}$

${ }^{1}$ K. Mey, Ann. d. Phys., Vol. II, p. 127.

${ }^{2}$ E. Riecke, Ann. d. Phys., Vol. 15, p. 1003.

${ }^{3}$ C. A. Skinner, Phys. Rev.,Vol. 21, p. I ; Phys. Zeitschr., 6, p. 6ro ; Phil. Mag., Vol. I2, p. $48 \mathrm{r}$.

${ }^{4}$ C. A. Skinner, Phys. Rev., Vol. 21 , p. 169.

${ }^{5}$ This plan had already been tried in this laboratory by Mr. Kiesselbach, who used several of the common metals with a limited degree of success. He found that they absorbed hydrogen from one to two minutes at the rate required by Faraday's law. 
[VoL. XXIX.

After first testing silver as anode, which was found to absorb hydrogen from two to four minutes at about the calculated rate, the alkali metals, sodium, potasssium, and a sodium-potassium alloy, were tried with marked success in a hydrogen and also in a nitrogen atmosphere. Finally mercury was tested, giving positive results in hydrogen but no absorption in nitrogen. In a few isolated cases out of a large number of tests helium was also absorbed by a sodium and by a mercury anode at double the rate (by volume) that hydrogen is under the same current. In most of the tests, however, practically no absorption of helium was obtained.

\section{Apparatus.}

A battery of small storage cells served for producing the glow current, which was regulated by a cadmium iodide and amyl alcohol resistance, and measured by a Weston milliammeter. The gases used were hydrogen, nitrogen and helium. Hydrogen, obtained from aluminium in a solution of potassium hydrate, was, after careful drying by phosphorus pentoxide, stored in a flask which had stood evacuated for a time sufficient to free it of occluded gases. Nitrogen was obtained by passing air through phosphorus vapor, through a wash bottle containing a potassium hydrate solution, and finally through a tube containing phosphorus pentoxide. After drying, it was also stored in a flask freed of occluded gases. The helium used was obtained in sealed glass bulbs from Messrs. Thomas Tyrer \& Co., London, from which it was transferred to another provided with a stop-cock, through which connection with the system was afforded.

In the vacuum system all ground joints and stop-cocks were lubricated with a mixture free of hydrocarbons. Phosphorus pentoxide was used as a drier. Evacuation was produced by a Barr and Stroud mercury pump. The pressure was measured by a McLeod gauge - one millimeter on the scale representing oI $\mathrm{mm}$. mercury pressure. The probable error in any measurement was not greater than $.005 \mathrm{~mm}$. although a maximum error of .OI $\mathrm{mm}$. might be made.

Experimental Results.

Silver as Anode. - The form of tube used for testing a silver anode in hydrogen is shown in Fig. I. It was of glass provided with 
the main electrodes $A$ (the anode of silver) and $C$ (the cathode of nickel), and an auxiliary electrode $B$ of aluminium wire. The cathode was chosen of nickel as this metal was found to give off as cathode less gas than the others. Both electrodes $A$ and $C$ were made removable and were always carefully polished before mounting for a test. These preparations having been made the tube was evacuated and helium, to a pressure of about two millimeters of mercury, admitted. A very strong

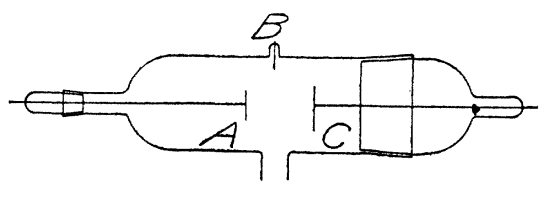

Fig. 1. glow current was then passed simultaneously from $A$ and $C$ as cathodes to $B$ as anode until the increase in gas pressure ceased. This cleaning current was made sufficiently intense to drive off the outer surface of the silver thus leaving a fresh surface which had been unexposed to other than the helium atmosphere. The success of all tests depended upon this treatment.

Having cleaned the electrodes in this manner the gas was quickly pumped out and hydrogen admitted. There was with all the metals tested a small gradual decrease in pressure of this gas for a time after admission arising from the absorption by the clean electrode and the metal deposited on the walls of the tube. ${ }^{1}$ The nickel electrode, however, did not appear from the tests to absorb any of this gas. When the pressure became constant the electric current was started, with the nickel as cathode and the silver as anode. The change in gas pressure with time, under a current of about one milliampere, for three different tests is given in Table I. and plotted in Fig. 4. In the plot the straight line represents the decrement in gas pressure calculated from the electrochemical equivalent of hydrogen $\left(\mathrm{IO} 4 \times \mathrm{IO}^{-7} \mathrm{gr}\right.$. per coulomb), its density at room temperature and $76 \mathrm{~cm}$. pressure $\left(83 \times 10^{-6}\right)$, and the volume of the tube ( 382 c.c.). It is to be noticed that for two minutes after the current started the decrease in pressure approximated closely the calculated value, from which it is to be concluded that with each atom of hydrogen absorbed is associated a negative charge of the same magnitude as that carried in solutions. When the surface of the metal

${ }^{1}$ See W. Heald, Phys. Rrv., Vol. 24, p. 269. 
[Vol. XXIX.

becomes saturated with the gas it is to be expected that the absorption will stop, or, as suggested by Skinner $(l . c$.$) , that uncharged gas$ will leave the metal as fast as the charged gas enters it. In the case of silver this condition was reached in a short time and absorption ceased abruptly.

Soda Glass as Anode. - The investigation was next directed to sodium with the hope of obtaining absorption of longer duration. It was introduced into the tube first by electrolysis of the glass according to Warburg's ${ }^{1}$ method. The tube used (shown in Fig. 2) was made of soda glass and furnished with a nickel

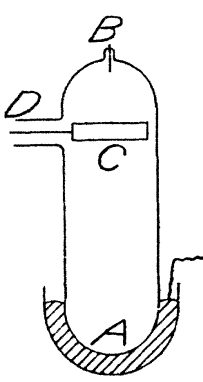

Fig. 2. electrode $C$ which in the tests served as cathode, and an auxiliary electrode $B$. The end of the tube was immersed in a cup containing sodium amalgam through which the tube was heated by a Bunsen flame to a temperature such that the current could be passed through the glass and from it as anode through the gas to the cathode. Before the test the cathode was freed of gas by passing a current from $B$ as anode. To obtain first a deposit of sodium inside the tube a glow current was passed through the glass and a helium atmosphere for a time before testing for the absorption of hydrogen. Having obtained the desired deposit the helium was removed and hydrogen admitted. The results from the different tests were very inconsistent, and, since the temperature was sufficient to deposit sodium (by vaporization) over the inner walls of the tube and on the other electrodes, the suggestion was that the natural absorption (or evolution of gas) by this deposit masked the effect of absorption by the anode.

Soda Glass as Cathode. - An interesting thing was noticed in connection with the tests of the conducting glass. When it was used as cathode in helium the gas pressure increased at a rate about equal to that calculated on the assumption that hydrogen was the carrier of the current from the cathode. The spectrum, however, indicated that the gas freed from the glass was nitrogen. Representative observations of the increase in gas pressure with time are 
given in Table II. Like those obtained by Skinner ${ }^{1}$ with a carbon electrode these results indicate that a negative electron is associated with each atom of nitrogen leaving the glass cathode. This is consistent with the fact that the chemical valence of nitrogen is in some cases unity. On reversing the current the gas which had been freed was reabsorbed (presumably by the glass), and on two occasions practically all of the helium atmosphere was absorbed with it.

Sodium Anode in Hydrogen. - To test the absorption of sodium at lower temperatures than the electrolytic method of introduction

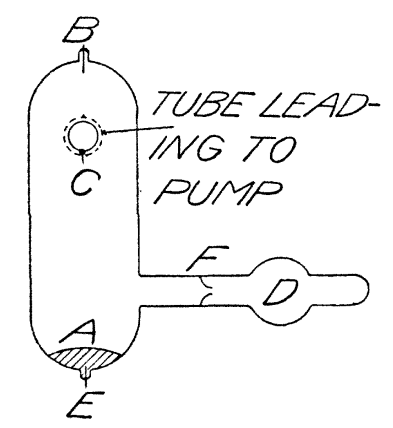

Fig. 3.

allowed, metallic sodium was introduced directly into the tube, the form of which is shown in Fig. 3. The sodium was first placed in the bulb $D$ and the end of this side tube sealed. During continuous operation of the evacuating pump the sodium was then

TABLE I.

Silver Anode in Hydrogen. Volume 382 c.c.

\begin{tabular}{|c|c|c|c|c|c|c|}
\hline \multirow{2}{*}{$\begin{array}{l}\text { Duration } \\
\text { Current } \\
\text { (Min.). }\end{array}$} & \multicolumn{2}{|c|}{$\begin{array}{l}\text { Current I ma. } \\
\text { Initial Pressure } 2.04 \mathrm{~mm} \text {. }\end{array}$} & \multicolumn{2}{|c|}{$\begin{array}{l}\text { Current I ma. } \\
\text { Initial Pressure } 1.7 \mathrm{~mm} \text {. }\end{array}$} & \multicolumn{2}{|c|}{$\begin{array}{l}\text { Current .9 ma. } \\
\text { Initial Pressure } .94 \mathrm{~mm} \text {. }\end{array}$} \\
\hline & $\begin{array}{c}\text { Pressure } \\
\text { Decrement. }\end{array}$ & $\begin{array}{l}\text { Calculated } \\
\text { Decrement. }\end{array}$ & $\begin{array}{c}\text { Pressure } \\
\text { Decrement. }\end{array}$ & $\begin{array}{l}\text { Calculated } \\
\text { Decrement. }\end{array}$ & $\begin{array}{c}\text { Pressure } \\
\text { Decrement. }\end{array}$ & $\begin{array}{l}\text { Calculated } \\
\text { Decrement. }\end{array}$ \\
\hline 1 & .02 & .015 & .015 & .015 & .01 & .0135 \\
\hline 2 & .035 & .03 & .025 & .03 & .02 & .026 \\
\hline 3 & .035 & .045 & .025 & .045 & .03 & .040 \\
\hline 4 & .04 & .06 & .02 & .06 & .04 & .054 \\
\hline 5 & .045 & .075 & & & .03 & .067 \\
\hline 6 & .05 & .09 & & & & \\
\hline
\end{tabular}

1 C. A. Skinner, Phys. Rev., Vol. 21, p. 168. 
TABLE II.

Glass Cathode in Helium.

\begin{tabular}{c|c|c|c|c}
\hline \multirow{2}{*}{$\begin{array}{c}\text { Duration } \\
\text { Current } \\
\text { (Min.). }\end{array}$} & \multicolumn{2}{c|}{$\begin{array}{c}\text { Current I ma. } \\
\text { Initial Pressure 2.21 mm. }\end{array}$} & \multicolumn{2}{|c|}{$\begin{array}{c}\text { Volume 277 c.c. } \\
\text { Initial Pressure 2.245 mm. }\end{array}$} \\
\cline { 2 - 3 } & $\begin{array}{c}\text { Pressure } \\
\text { Increment. }\end{array}$ & $\begin{array}{c}\text { Calculated } \\
\text { Increment. }\end{array}$ & $\begin{array}{c}\text { Pressure } \\
\text { Increment. }\end{array}$ & $\begin{array}{c}\text { Calculated } \\
\text { Increment. }\end{array}$ \\
\hline 1 & .02 & .0207 & .025 & .019 \\
2 & .04 & .041 & .045 & .038 \\
3 & .06 & .062 & .065 & .057 \\
4 & .07 & .083 & .075 & .076 \\
5 & .08 & .104 & .085 & .096 \\
6 & & & .09 & .113 \\
7 & & & .095 & .132 \\
\hline
\end{tabular}

TABle III.

Sodium Anode in Hydrogen.

\begin{tabular}{|c|c|c|c|c|c|c|}
\hline \multirow{2}{*}{$\begin{array}{l}\text { Duration } \\
\text { Current } \\
\text { (Min.). }\end{array}$} & \multicolumn{2}{|c|}{$\begin{array}{l}\text { Current I ma. } \\
\text { Volume } 263 \text { c.c. } \\
\text { Initial Pressure } 1.84 \mathrm{~mm} \text {. }\end{array}$} & \multicolumn{2}{|c|}{$\begin{array}{c}\text { Current .5 ma. } \\
\text { Volume } 263 \text { c.c. } \\
\text { Initial Pressure 2.165 mm. }\end{array}$} & \multicolumn{2}{|c|}{$\begin{array}{c}\text { Current } 1.5 \mathrm{ma} . \\
\text { Volume } 268 \mathrm{c.c} \text {. } \\
\text { Initial Pressure } 1.6 \mathrm{~mm} \text {. }\end{array}$} \\
\hline & $\begin{array}{c}\text { Pressure } \\
\text { Decrement. }\end{array}$ & $\begin{array}{l}\text { Calculated } \\
\text { Decrement. }\end{array}$ & $\begin{array}{c}\text { Pressure } \\
\text { Decrement. }\end{array}$ & $\begin{array}{l}\text { Calculated } \\
\text { Decrement. }\end{array}$ & $\begin{array}{c}\text { Pressure } \\
\text { Decrement. }\end{array}$ & $\begin{array}{l}\text { Calculated } \\
\text { Decrement. }\end{array}$ \\
\hline 1 & .025 & .022 & .02 & .011 & .03 & .032 \\
\hline 2 & .05 & .043 & .03 & .021 & .055 & .064 \\
\hline 3 & .07 & .065 & .04 & .032 & .08 & .096 \\
\hline 4 & .095 & .085 & .045 & .043 & .11 & .128 \\
\hline 5 & .115 & .109 & .05 & .053 & .13 & .160 \\
\hline 6 & .14 & .131 & .06 & .065 & .16 & .192 \\
\hline 7 & .16 & .151 & .07 & .075 & .18 & .224 \\
\hline 8 & .18 & .174 & .08 & .086 & .21 & .256 \\
\hline 9 & .205 & .196 & .085 & .096 & .23 & .288 \\
\hline 10 & .225 & .218 & .095 & .107 & .25 & .320 \\
\hline 11 & .25 & .240 & .01 & .118 & .27 & .352 \\
\hline 12 & .27 & .262 & .11 & .128 & .29 & .384 \\
\hline 13 & .29 & .283 & .11 & .139 & .31 & .416 \\
\hline 14 & .31 & .305 & & & .33 & .448 \\
\hline 15 & .33 & .327 & & & .34 & .480 \\
\hline 16 & .345 & .349 & & & & \\
\hline 17 & .36 & .371 & & & & \\
\hline 18 & .38 & .392 & & & & \\
\hline 19 & .39 & .414 & & & & \\
\hline 20 & .41 & .436 & & & & \\
\hline 21 & .43 & .458 & & & & \\
\hline 22 & .45 & .479 & & & & \\
\hline 23 & .46 & .501 & & & & \\
\hline 24 & .48 & .523 & & & & \\
\hline 25 & .49 & .545 & & & & \\
\hline 26 & .50 & .567 & & & & \\
\hline
\end{tabular}


melted and allowed to flow through the trap $F$ into the bottom of the tube at $A$ where electric connection with it was made by a platinum wire sealed in at $E$. Preliminary to testing for the ab-

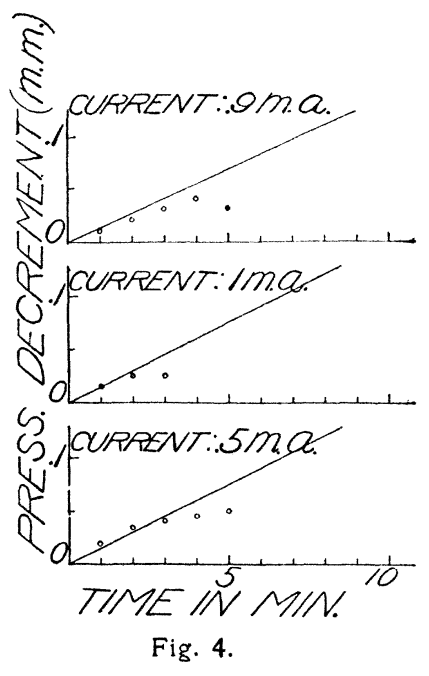

sorption of hydrogen the sodium and nickel $C$ were freed of gas as before by using them as cathodes with a very strong glow current in helium.

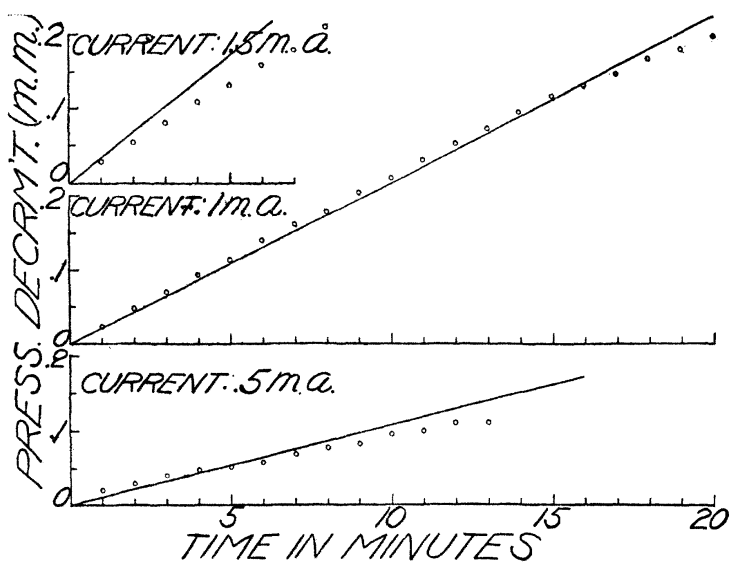

Fig. 5.

In Table III. and Fig. 5 is given, for the sodium as anode and nickel as cathode, the decrease in pressure of a hydrogen atmos- 
phere with duration of current. Since absorption continued much longer than with a silver anode the initial pressure of the gas was taken at the end of the first minute to eliminate the effect of a change in temperature and the excess of initial absorption caused by starting the current. With .5 milliampere the absorption agreed with the calculated value for about ten minutes but stopped completely at the end of twelve minutes. With I milliampere it followed the calculated value for I 5 minutes and continued slowly even after twenty-six minutes. With 1.5 milliamperes absorption according to the calculated rate lasted for only two minutes although it continued to absorb slowly for fifteen. The short duration in the last case is ascribed to a less favorable condition of the metal surface. It was noticed that during the absorption the surface of

TABLE IV.

Potassium Anode in Hydrogen. Volume 276 c.c.

\begin{tabular}{|c|c|c|c|c|}
\hline \multirow{2}{*}{$\begin{array}{l}\text { Duration } \\
\text { Current } \\
\text { (Min.). }\end{array}$} & \multicolumn{2}{|c|}{$\begin{array}{l}\text { Current I ma. } \\
\text { Initial Pressure } 1.67 \mathrm{~mm} \text {. }\end{array}$} & \multicolumn{2}{|c|}{$\begin{array}{l}\text { Current . } 5 \mathrm{ma} . \\
\text { Initial Pressure } 1.985 \mathrm{~mm} \text {. }\end{array}$} \\
\hline & $\begin{array}{c}\text { Pressure } \\
\text { Decrement. }\end{array}$ & $\begin{array}{c}\text { Calculated } \\
\text { Decrement. }\end{array}$ & $\begin{array}{c}\text { Pressure } \\
\text { Decrement. }\end{array}$ & $\begin{array}{l}\text { Calculated } \\
\text { Decrement. }\end{array}$ \\
\hline 1 & .02 & .021 & .01 & .0104 \\
\hline 2 & .04 & .042 & .02 & .021 \\
\hline 3 & .06 & .062 & .035 & .031 \\
\hline 4 & .075 & .083 & .045 & .042 \\
\hline 5 & .095 & .104 & .055 & .052 \\
\hline 6 & .115 & .125 & .065 & .062 \\
\hline 7 & .135 & .146 & .08 & .073 \\
\hline 8 & .155 & .166 & .09 & .083 \\
\hline 9 & .170 & .187 & .10 & .094 \\
\hline 10 & .19 & .208 & .11 & .104 \\
\hline 11 & .21 & .229 & .125 & .114 \\
\hline 12 & .22 & .250 & .135 & .125 \\
\hline 13 & & & .145 & .135 \\
\hline 14 & & & .155 & .146 \\
\hline 15 & & & .165 & .156 \\
\hline 16 & & & .175 & .166 \\
\hline 17 & & & .185 & .177 \\
\hline 18 & & & .200 & .187 \\
\hline 19 & & & .21 & .198 \\
\hline 20 & & & .22 & .208 \\
\hline 21 & & & .225 & .218 \\
\hline 22 & & & .235 & .229 \\
\hline 23 & & & .235 & .248 \\
\hline
\end{tabular}


the sodium was blackened, indicating that sodium hydride was being formed. By using the sodium as cathode in a helium atmosphere it was found that this surface was almost entirely cleaned off under a strong current, and the disappearance accompanied by an increase in gas pressure slightly greater than the amount of hydrogen previously absorbed.

Potassium Anode in Hydrogen. - The form of tube used with the potassium, and the treatment of the metal, were the same as with sodium. The results of tests made under similar conditions are given in Table IV. and plotted in Fig. 6 . Of these the .5 milli-

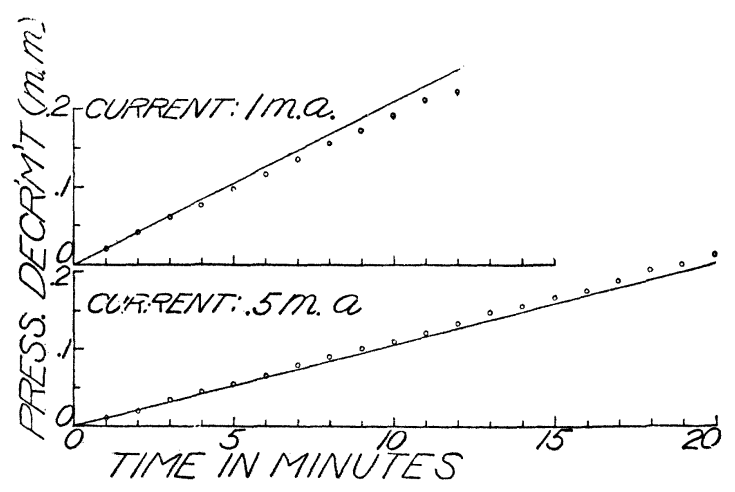

Fig. 6.

ampere gave the best results. The absorption followed the calculated value for twenty-two minutes and then suddenly stopped. With I milliampere absorption lasted for twelve minutes slightly below the calculated value. The test with 1.5 milliamperes gave no absorption, arising undoubtedly from an unfavorable condition of the surface of the metal.

Sodium-Potassium Anode in Hydrogen. - Sodium and potassium alloyed in atomic ratio was tested in the same form of tube and treated in the same manner as the two preceding metals. The results are given in Table V. and plotted in Fig. 7. With .5 milliampere the absorption followed closely the calcutated value for eight minutes, then suddenly stopped. With I milliampere it lasted about eleven minutes at a rate slightly below that calculated, while with 1.5 milliamperes agreement with the calculated value only lasted for about three minutes. 
TABLE V.

Sodium-Potassium Anode in Hydrogen. Volume 273 c.c.

\begin{tabular}{|c|c|c|c|c|c|c|}
\hline \multirow{2}{*}{$\begin{array}{l}\text { Duration } \\
\text { Current } \\
\text { (Min.). }\end{array}$} & \multicolumn{2}{|c|}{$\begin{array}{l}\text { Current I ma. } \\
\text { Initial Pressure 2.375 } \mathrm{mm} \text {. }\end{array}$} & \multicolumn{2}{|c|}{$\begin{array}{l}\text { Current } .5 \mathrm{ma} \text {. } \\
\text { Initial Pressure } 2.24 \mathrm{~mm} \text {. }\end{array}$} & \multicolumn{2}{|c|}{$\begin{array}{l}\text { Current } 1.5 \mathrm{ma} \text {. } \\
\text { Initial Pressure } 1.455 \mathrm{~mm} \text {. }\end{array}$} \\
\hline & $\begin{array}{c}\text { Pressure } \\
\text { Decrement. }\end{array}$ & $\begin{array}{l}\text { Calculated } \\
\text { Decrement. }\end{array}$ & $\begin{array}{c}\text { Pressure } \\
\text { Decrement. }\end{array}$ & $\begin{array}{l}\text { Calculated } \\
\text { Decrement. }\end{array}$ & $\begin{array}{c}\text { Pressure } \\
\text { Decrement. }\end{array}$ & $\begin{array}{l}\text { Calculated } \\
\text { Decrement. }\end{array}$ \\
\hline 1 & .02 & .021 & .015 & .0105 & .03 & .0315 \\
\hline 2 & .045 & .042 & .025 & .021 & .06 & .063 \\
\hline 3 & .06 & .063 & .035 & .032 & .09 & .094 \\
\hline 4 & .08 & .084 & .04 & .042 & .11 & .126 \\
\hline 5 & .10 & .105 & .05 & .053 & .13 & .158 \\
\hline 6 & .12 & .126 & .06 & .063 & .145 & .221 \\
\hline 7 & .14 & .147 & .07 & .074 & & \\
\hline 8 & .16 & .168 & .08 & .084 & & \\
\hline 9 & .18 & .189 & .08 & .095 & & \\
\hline 10 & .20 & .21 & & & & \\
\hline 11 & .22 & .231 & & & & \\
\hline 12 & .23 & .252 & & & & \\
\hline 13 & .24 & .273 & & & & \\
\hline 14 & .26 & .294 & & & & \\
\hline 15 & .275 & .315 & & & & \\
\hline
\end{tabular}

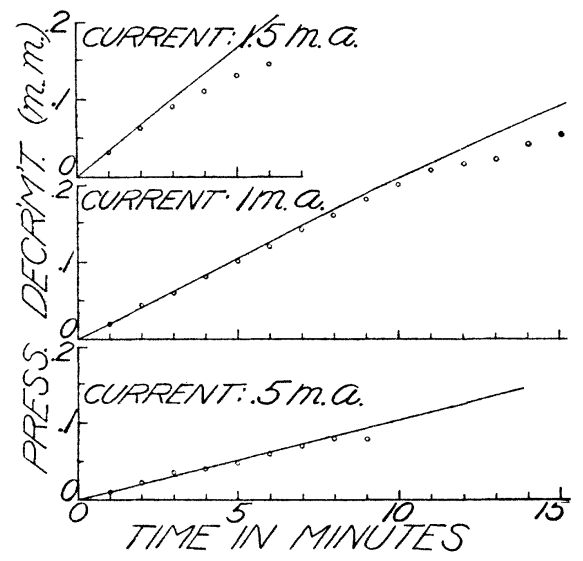

Fig. 7.

Mercury Anode in Hydrogen. - The form of tube used and the treatment of this metal was the same as with the alkali metals. The amount of hydrogen absorbed by the mercury before the current started was found to be much greater than in any other cases. In Table VI. is given a series of observations showing the gradual 
TABLE VI.

The Absorption of Hydrogen by Mercury without Current. Volume 290 c.c.

$\begin{array}{ccc}\text { Time(Min.). } & \text { Gas Pressure (mm.). } & \text { Pressure Decrement. } \\ 0 & 2.41 & .0 \\ 1 & 2.4 & .01 \\ 2 & 2.39 & .02 \\ 3 & 2.38 & .03 \\ 4 & 2.38 & .03 \\ 5 & 2.365 & .045 \\ 6 & 2.37 & .04 \\ 7 & 2.365 & .045\end{array}$

change in pressure of hydrogen after simply being admitted into the discharge tube. The results of its absorption by mercury as anode are given in Table VII. and Fig. 8. All tests show first an exces-

TABLE VII.

Mercury Anode in Hydrogen.

\begin{tabular}{|c|c|c|c|c|c|c|}
\hline \multirow{2}{*}{$\begin{array}{l}\text { Duration } \\
\text { Current } \\
\text { (Min.). }\end{array}$} & \multicolumn{2}{|c|}{$\begin{array}{c}\text { Current I ma. } \\
\text { Volume } 295 \mathrm{c.c} . \\
\text { Initial Pressure } 2.03 \mathrm{~mm} \text {. }\end{array}$} & \multicolumn{2}{|c|}{$\begin{array}{c}\text { Current r.5 ma. } \\
\text { Volume } 290 \mathrm{ccc} . \\
\text { Initial Pressure } 283 \mathrm{~mm} \text {. }\end{array}$} & \multicolumn{2}{|c|}{$\begin{array}{c}\text { Current 2 ma. } \\
\text { Volume 290 c.c. } \\
\text { Initial Pressure } 3.18 \mathrm{~mm} .\end{array}$} \\
\hline & $\begin{array}{c}\text { Pressure } \\
\text { Decrement. }\end{array}$ & $\begin{array}{l}\text { Calculated } \\
\text { Decrement. }\end{array}$ & $\begin{array}{c}\text { Pressure } \\
\text { Decrement. }\end{array}$ & $\begin{array}{l}\text { Calculated } \\
\text { Decrement. }\end{array}$ & $\begin{array}{c}\text { Pressure } \\
\text { Decrement. }\end{array}$ & $\begin{array}{l}\text { Calculated } \\
\text { Decrement. }\end{array}$ \\
\hline 1 & .03 & .0194 & .08 & .0297 & .11 & .0396 \\
\hline 2 & .055 & .039 & .15 & .059 & .18 & .079 \\
\hline 3 & .085 & .058 & .18 & .089 & .22 & .119 \\
\hline 4 & .11 & .078 & .22 & .119 & .27 & .158 \\
\hline 5 & .135 & .097 & .25 & 149 & .31 & .198 \\
\hline 6 & .155 & .116 & .28 & .178 & .35 & .237 \\
\hline 7 & .175 & .136 & .32 & .208 & .39 & .277 \\
\hline 8 & .195 & .155 & .34 & .238 & .42 & .317 \\
\hline 9 & .215 & .175 & .37 & .267 & .44 & .356 \\
\hline 10 & .235 & .194 & .395 & .297 & .455 & .396 \\
\hline 11 & .25 & .214 & & & & \\
\hline 12 & .27 & .233 & & & & \\
\hline 13 & .285 & .252 & & & & \\
\hline 14 & .30 & .272 & & & & \\
\hline 15 & .315 & .291 & & & & \\
\hline 16 & .33 & .311 & & & & \\
\hline
\end{tabular}

sive initial absorption but later agree with the calculated rate. With I. 5 and 2 milliamperes agreement is found between the two minute and the eight and ten minute points, while with I milliampere it is between the three and fifteen minute points. The excessive initial 
absorption which was so marked with mercury took place to a slight degree also with the alkali metals. With them, however, it occurred within the first minute after the current started so that the effect was eliminated by beginning observations after this time had elapsed. This excessive absorption during the first few minutes of current

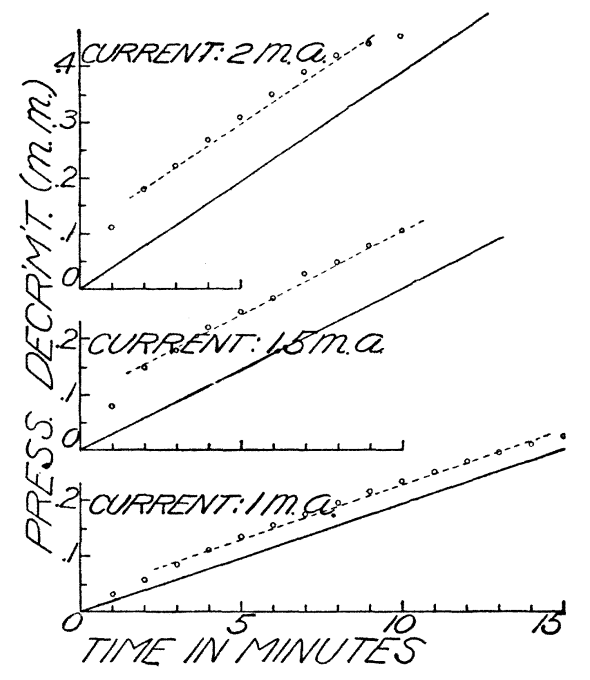

Fig. 8.

indicates that the metal will absorb more uncharged gas in a conducting state than when non-conducting. It is probably related to the fact noted by the writer ${ }^{1}$ in an earlier paper that the photoelectric activity of a metal when placed in an atmosphere of hydrogen increased far more rapidly when the gas was conductive than when not.

Sodium Anode in Nitrogen. - The tests in hydrogen were followed by similar ones in nitrogen - the form of tube and treatment of the metal being the same. The results of the absorption of nitrogen by a sodium anode are given in Table VIII. and plotted in Fig. 9. The calculated value assumes that each atom absorbed carries the same charge as hydrogen. Absorption was not of as long duration as in the case of hydrogen. With .5 milliampere it agreed with that calculated for the first five minutes, then practically stopped; with I milliampere it agreed for the first four minutes and 1 V. L. Chrisler, Phys. Rev., vol. 27, p. 267. 
TABLE VIII.

Sodium Anode in Nitrogen. Volume 295 c.c.

\begin{tabular}{c|c|c|c|c}
\hline \multirow{2}{*}{$\begin{array}{c}\text { Duration } \\
\text { Current } \\
\text { (Min.). }\end{array}$} & \multicolumn{2}{|c|}{$\begin{array}{c}\text { Current r ma. } \\
\text { Initial Pressure 3.65 mm. }\end{array}$} & \multicolumn{2}{c}{$\begin{array}{c}\text { Current .5 ma. } \\
\text { Initial Pressure 2.4 mm. }\end{array}$} \\
\cline { 3 - 5 } $\begin{array}{c}\text { Pressure } \\
\text { Decrement. }\end{array}$ & $\begin{array}{c}\text { Calculated } \\
\text { Decrement. }\end{array}$ & $\begin{array}{c}\text { Pressure } \\
\text { Decrement. }\end{array}$ & $\begin{array}{c}\text { Calculated } \\
\text { Decrement. }\end{array}$ \\
\hline 1 & .02 & .0194 & .01 & .010 \\
2 & .04 & .039 & .025 & .019 \\
3 & .06 & .058 & .03 & .029 \\
4 & .08 & .078 & .04 & .039 \\
5 & .09 & .097 & .05 & .049 \\
6 & .105 & .116 & .05 & .059 \\
7 & .12 & .136 & .055 & .068 \\
8 & .13 & .146 & & \\
\hline
\end{tabular}

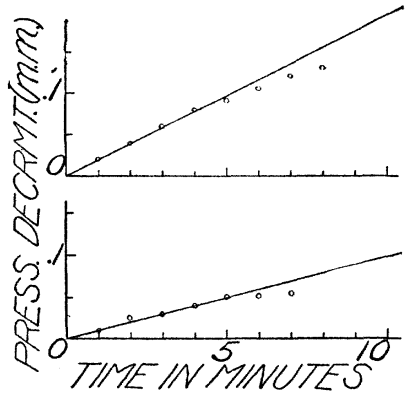

Fig. 9.

finally stopped at the end of eight minutes. A test with I.5 milliamperes gave no absorption, probably owing to unfavorable surface conditions or possibly because the current density was too great.

Potassium Anode in Nitrogen. - The results showing the absorption of nitrogen by a potassium anode are given in Table IX. and Fig. IO. The duration of absorption was about the same as with sodium. The .5 milliampere gave the best results, the absorption agreeing closely with that calculated for five minutes and stopping entirely at the end of six minutes. With I milliampere the absorption followed the calculated value for four minutes, while I.5 milliamperes agreed with that calculated for only two minutes.

Sodium-Potassium Anode in Nitrogen. - Results of absorption of nitrogen by this alloy are found in Table X. and Fig. I I. It lasted 
TABLE IX.

Potassium Anode in Nitrogen. Volume 295 c.c.

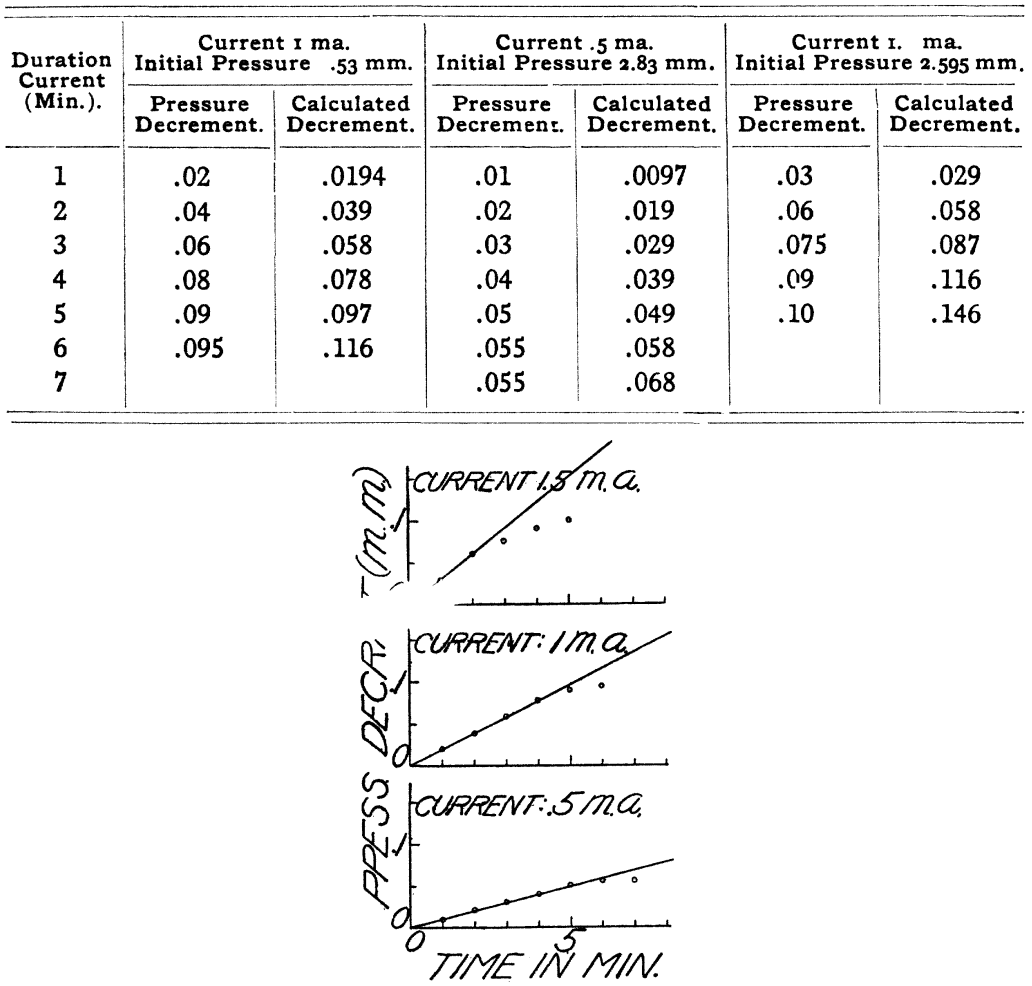

Fig. 10.

longer than with either sodium or potassium. With I milliampere the absorption was, for the first two minutes, greater than calculated, probably for the same reason that mercury absorbed an excessive amount of hydrogen for the first two or three minutes. Between the two and 15 minute points the rate agreed quite closely with that calculated. A current of .5 milliampere gave absorption which agreed fairly well with the calculated value for ten minutes while with I. 5 milliamperes it agreed for three minutes.

Glass, Sodium and Mercury Anodes in Helium. - It was noticed when depositing sodium by electrolysis of glass, using an atmosphere of helium, that the helium was sometimes absorbed. In sev- 
TABLE X.

Sodium-Potassium Anode in Nitrogen. Volume 295 c.c.

\begin{tabular}{|c|c|c|c|c|c|c|}
\hline \multirow{2}{*}{$\begin{array}{l}\text { Duration } \\
\text { Current } \\
\text { (Min.). }\end{array}$} & \multicolumn{2}{|c|}{$\begin{array}{l}\text { Current I ma. } \\
\text { Initial Pressure } 2.73 \mathrm{~mm} \text {. }\end{array}$} & \multicolumn{2}{|c|}{$\begin{array}{l}\text { Current } .5 \mathrm{ma} \text {. } \\
\text { Initial Pressure } 2.48 \mathrm{~mm} \text {. }\end{array}$} & \multicolumn{2}{|c|}{$\begin{array}{l}\text { Current I } 5 \mathrm{ma} . \\
\text { Initial Pressure } 2.02 \mathrm{~mm} \text {. }\end{array}$} \\
\hline & $\begin{array}{c}\text { Pressure } \\
\text { Decrement. }\end{array}$ & $\begin{array}{l}\text { Calculated } \\
\text { Decrement. }\end{array}$ & $\begin{array}{c}\text { Pressure } \\
\text { Decrement. }\end{array}$ & $\begin{array}{l}\text { Calculated } \\
\text { Decrement. }\end{array}$ & $\begin{array}{c}\text { Pressure } \\
\text { Decrement. }\end{array}$ & $\begin{array}{l}\text { Calculated } \\
\text { Decrement. }\end{array}$ \\
\hline 1 & .03 & .0194 & .01 & .0097 & .03 & .0291 \\
\hline 2 & .07 & .039 & .02 & .019 & .06 & .058 \\
\hline 3 & .09 & .058 & .04 & .029 & .085 & .087 \\
\hline 4 & .11 & .078 & .05 & .039 & .11 & .116 \\
\hline 5 & .13 & .097 & .06 & .049 & .13 & .146 \\
\hline 6 & .15 & .116 & .07 & .058 & .14 & .175 \\
\hline 7 & .17 & .136 & .08 & .068 & & \\
\hline 8 & .185 & .155 & .09 & .078 & & \\
\hline 9 & .205 & .175 & .10 & .087 & & \\
\hline 10 & .225 & .194 & .11 & .097 & & \\
\hline 11 & .24 & .213 & .115 & .107 & & \\
\hline 12 & .26 & .233 & .115 & .116 & & \\
\hline 13 & .275 & .252 & & & & \\
\hline 14 & .29 & .272 & & & & \\
\hline 15 & .315 & .291 & & & & \\
\hline 16 & .325 & .311 & & & & \\
\hline 17 & .345 & .330 & & & & \\
\hline 18 & .355 & .349 & & & & \\
\hline
\end{tabular}

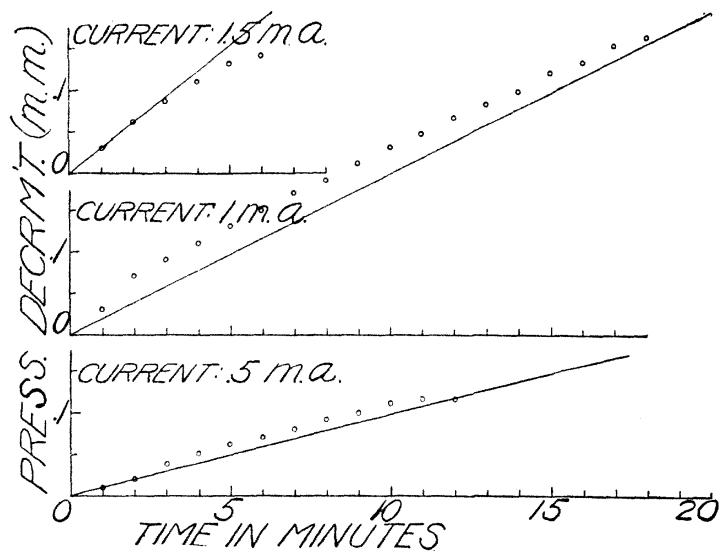

Fig. 11.

eral cases it was in only relatively small quantities, but in two others practically all of it was absorbed. The maximum rate of absorption in these two cases, which was attained a few minutes after the cur- 
rent started, lasted for several minutes in approximate agreement with that obtained later with sodium and mercury anodes. Results obtained from these two metals are given in Table XI. and Fig. I 2.

TABLE XI.

\begin{tabular}{c|c|c|c|c}
\hline & \multicolumn{2}{|c|}{$\begin{array}{c}\text { Mercury Anode in Helium. } \\
\text { Current I ma. } \\
\begin{array}{c}\text { Duration } \\
\text { Current } \\
\text { (Min.). }\end{array}\end{array}$} & $\begin{array}{c}\text { Volume 295 c.c. } \\
\text { Initial Pressure 2.845 mm. }\end{array}$ & \multicolumn{2}{|c}{$\begin{array}{c}\text { Sodium Anode in Helium. } \\
\text { Current I ma. } \\
\text { Initial Pressure r.05 mm. }\end{array}$} \\
\cline { 2 - 3 } \begin{tabular}{c|c|c|c} 
Volume 297 c.c. \\
Decrement.
\end{tabular} & $\begin{array}{c}\text { Calculated } \\
\text { Decrement. }\end{array}$ & $\begin{array}{c}\text { Pressure } \\
\text { Decrement. }\end{array}$ & $\begin{array}{c}\text { Calculated } \\
\text { Decrement. }\end{array}$ \\
\hline 1 & .035 & .0388 & .04 & .0386 \\
2 & .075 & .078 & .08 & .077 \\
3 & .105 & .116 & .11 & .116 \\
4 & .125 & .155 & .14 & .154 \\
5 & .155 & .194 & .16 & .193 \\
6 & .165 & .233 & .17 & .232 \\
7 & .175 & .273 & .18 & .270 \\
8 & .195 & .310 & .20 & .308 \\
9 & .205 & .349 & .21 & .347 \\
\hline
\end{tabular}

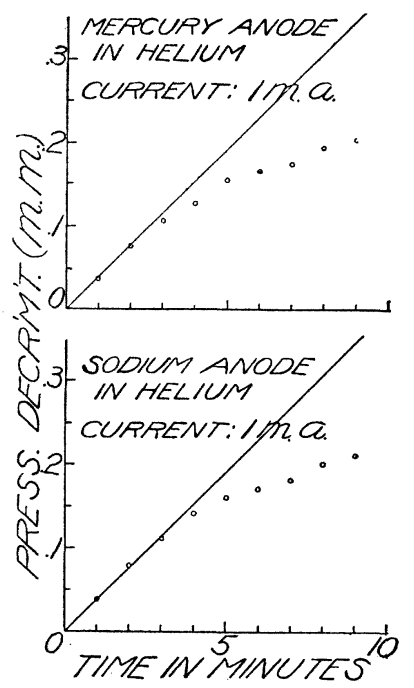

Fig. 12.

In the case of the sodium the helium used had been stored for several months in the bulb and hence might have been impure. That used with mercury, however, was fresh, having been transferred from the sealed glass bulb, in which it was obtained only a few 
days before the test. In both cases the results agree with each other very closely, giving a decrement in pressure just twice that which would have occurred had the same current passed through an atmosphere of hydrogen instead of helium. The calculated value was obtained by assuming that helium is monatomic and that with each atom absorbed there was associated the same charge as with hydrogen and nitrogen. Close agreement is found for the first three minutes after the current was started. Several attempts were made later to reproduce these results, but without success, probably owing to the fact that proper surface conditions were not obtained. The rate of absorption in the successful experiments as well as the failures to obtain any absorption indicate that the effects did not arise from the presence of the common gases as an impurity in the helium, because with these absorption always took place and at a distinctly different rate.

To sum up, it has been shown by the foregoing tests that hydrogen is absorbed by sodium, potassium, a sodium-potassium alloy and mercury when used as anode in a glow current, at such a rate as to indicate that with each atom absorbed is associated a negative charge of the same magnitude as the positive carried by it in solutions. The same has also been shown with nitrogen, using sodium, potassium and a sodium-potassium alloy as anode; and in two cases, with helium, using sodium and mercury as anodes. The fact that nitrogen carries the same charge as hydrogen is consistent with the chemical valence of nitrogen, being in some cases unity. Rutherford ${ }^{1}$ has concluded from his experiments that the $\alpha$ particle from radium is a helium atom carrying a positive charge of twice the magnitude of that carried by a hydrogen atom in solution, while the results given here indicate on the other hand that with the helium atom is associated a negative charge of the same magnitude as that carried by hydrogen.

I wish here to express my appreciation and thanks to Dr. C. A. Skinner, of the University of Nebraska, for his help and inspiration to me in this work.

The Brace Laboratory of Physics,

University of Nebraska, LinColn, June, 1909.

1E. Rutherford, Phil. Mag., p. 281, February, 1909. 